University of Nebraska - Lincoln

DigitalCommons@University of Nebraska - Lincoln

Faculty Publications: Department of Entomology

August 2000

\title{
Fipronil metabolism, oxidative sulfone formation and toxicity among organophosphate- and carbamate-resistant and susceptible western corn rootworm populations
}

\author{
Michael E. Scharf \\ University of Nebraska-Lincoln \\ Blair D. Siegfried \\ University of Nebraska-Lincoln, bsiegfried1@ufl.edu \\ Lance J. Meinke \\ University of Nebraska-Lincoln, Imeinke1@unl.edu \\ Laurence D. Chandler \\ Northern Grain Insects Research Laboratory, USDA-ARS
}

Follow this and additional works at: https://digitalcommons.unl.edu/entomologyfacpub

Part of the Entomology Commons

Scharf, Michael E.; Siegfried, Blair D.; Meinke, Lance J.; and Chandler, Laurence D., "Fipronil metabolism, oxidative sulfone formation and toxicity among organophosphate- and carbamate-resistant and susceptible western corn rootworm populations " (2000). Faculty Publications: Department of Entomology. 7.

https://digitalcommons.unl.edu/entomologyfacpub/7

This Article is brought to you for free and open access by the Entomology, Department of at DigitalCommons@University of Nebraska - Lincoln. It has been accepted for inclusion in Faculty Publications: Department of Entomology by an authorized administrator of DigitalCommons@University of Nebraska - Lincoln. 


\title{
Fipronil metabolism, oxidative sulfone formation and toxicity among organophosphate- and carbamate-resistant and susceptible western corn rootworm populations $^{\dagger}$
}

\author{
Michael E Scharf, ${ }^{1}$ Blair D Siegfried, ${ }^{1 *}$ Lance J Meinke ${ }^{1}$ and Laurence D Chandler ${ }^{2}$ \\ ${ }^{1}$ Department of Entomology, University of Nebraska, Lincoln, NE 68583-0816, USA \\ ${ }^{2}$ Northern Grain Insects Research Laboratory, USDA-ARS, 2923 Medary Avenue, Brooking, SD, 57006, USA
}

\begin{abstract}
Fipronil toxicity and metabolism were studied in two insecticide-resistant, and one susceptible western corn rootworm (Diabrotica virgifera virgifera, LeConte) populations. Toxicity was evaluated by exposure to surface residues and by topical application. Surface residue bioassays indicated no differences in fipronil susceptibility among the three populations. Topical bioassays were used to study the relative toxicity of fipronil, fipronil + the mono-oxygenase inhibitor piperonyl butoxide, and fipronil's oxidative sulfone metabolite in two populations (one resistant with elevated mono-oxygenase activity). Fipronil and fipronil-sulfone exhibited similar toxicity and application of piperonyl butoxide prior to fipronil resulted in marginal effects on toxicity. Metabolism of $\left[{ }^{14} \mathrm{C}\right]$ fipronil was evaluated in vivo and in vitro in the three rootworm populations. In vivo studies indicated the dominant pathway in all populations to be formation of the oxidative sulfone metabolite. Much lower quantities of polar metabolites were also identified. In vitro studies were performed using sub-cellular protein fractions (microsomal and cytosolic), and glutathione-agarose purified glutathione- $S$ transferase. Oxidative sulfone formation occurred almost exclusively in in vitro microsomal reactions and was increased in the resistant populations. Highly polar metabolites were formed exclusively in in vitro cytosolic reactions. In vitro reactions performed with purified, cytosolic glutathione- $S$ transferase $(M W=27 \mathrm{kDa})$ did not result in sulfone formation, although three additional polar metabolites not initially detectable in crude cytosolic reactions were detected. Metabolism results indicate both cytochromes $\mathrm{P} 450$ and glutathione- $S$-transferases are important to fipronil metabolism in the western corn rootworm and that toxic sulfone formation by $\mathbf{P 4 5 0}$ does not affect net toxicity. (C) 2000 Society of Chemical Industry
\end{abstract}

Keywords: fipronil; phenylpyrazole; insecticide resistance; cytochrome P450; glutathione-S-transferase; corn rootworm; Diabrotica virgifera virgifera

\section{INTRODUCTION}

Fipronil is a halogen-substituted, thioether-containing phenylpyrazole insecticide which acts as an agonist at the gamma-aminobutyric acid (GABA)-gated chloride channel/ionopore complex, and which possesses a high level of toxicity to insects because of its specificity to this target site. ${ }^{1}$ Studies examining the effects of the mono-oxygenase inhibitor piperonyl butoxide (PBO) on fipronil toxicity have found antagonism of toxicity to occur in Blattella germanica $\mathrm{L}^{2,3}$ but not Musca domestica L. $^{3,4}$ Similar PBO antagonism was observed in $M$ domestica for a modified thioether analog of fipronil (sulfur not substituted with oxygen). ${ }^{4}$ Taken together, these results suggest that, in some insect groups or populations, oxidative metabolism of fipronil may enhance toxicity. In this regard, Brookhart and Bushey ${ }^{5}$ identified an oxidative sulfone metabolite in studies investigating the metabolism of $\left[{ }^{14} \mathrm{C}\right]$ fipronil by Spodoptera eridanea Cram. Fipronil and fipronil-sulfone were later compared in their neurophysiological effects and toxicity in the western corn rootworm, ${ }^{6}$ and it was found that both elicited similar toxicities and increases in spontaneous electrical activity at the ventral nerve cord.

In Nebraska, western corn rootworm (Diabrotica virgifera virgifera, LeConte) populations have recently

\footnotetext{
* Correspondence to: Blair D Siegfried, Department of Entomology, University of Nebraska, Lincoln, NE 68583-0816, USA

$\dagger$ This article reports results of research only. Mention of a proprietary product does not constitute an endorsement or a recommendation by the USDA for its use

Contract/grant sponsor: Rhone-Poulenc Ag Co

Contract/grant sponsor: USDA-ARS specific cooperative agreement; contract/grant number: 58-5447-6-116

(Received 4 November 1999; revised version received 1 February 2000; accepted 11 April 2000)
} 
evolved resistance to a number of insecticides from different neurotoxic classes. ${ }^{7}$ Physiological adaptations responsible for resistance include elevated esterase-based hydrolysis and cytochrome P450-based oxidation. $^{8-10}$ In addition, insecticide resistance and related mechanisms have been identified in both rootworm adults and larvae. ${ }^{11}$ The primary method of rootworm population management in Nebraska has been to apply insecticides aerially so as to limit egg production in adults and protect corn plants from damage by larval offspring in the following growing season. Larval management by soil insecticide application is practiced to a much greater extent in other areas of the US corn belt than in Nebraska and, at present, resistance appears limited to Nebraska (Scharf et $a l^{9}$ and LJ Meinke unpublished results). However, because resistance extends to larvae, migration to other areas of corn production could present a substantial threat to US agriculture (as has occurred previously, see Metcalf ${ }^{12}$ ). It is for this reason that viable alternatives continue to be investigated which could potentially be used to limit the present distribution of resistance in Nebraska western corn rootworms.

These studies were undertaken to develop a better understanding of processes involved in fipronil toxicity in insects, and to determine the potential role of fipronil as a resistance management tool. Using wellcharacterized, insecticide-resistant and susceptible western corn rootworm populations, the general objectives of these studies were to investigate: (1) the relative toxicity of fipronil among these populations; (2) the effects of PBO on fipronil toxicity and the toxicity of fipronil relative to its oxidative sulfone metabolite; and (3) the metabolism of $\left[{ }^{14} \mathrm{C}\right]$ fipronil using in vivo and in vitro techniques so that affiliated enzyme systems could be identified.

\section{MATERIALS AND METHODS}

\subsection{Chemicals}

[Phenyl- ${ }^{14} \mathrm{C}$ ] fipronil $\left(26.5 \mathrm{mCi} \mathrm{mmol}^{-1}\right)$ and the nonradiolabeled standards (\% AI): fipronil (97.1\%), fipronil-sulfone (99.9\%), and fipronil-sulfide (98.8\%) were supplied by Rhone Poulenc Ag Co (Research Triangle Park, NC). Prior to the initiation of experiments, $\left[{ }^{14} \mathrm{C}\right]$ fipronil was purified by thin layer chromatography (TLC). Piperonyl butoxide (PBO) was obtained from Crescent Chemical Co (Hauppage, NY). All electrophoresis materials were purchased from Bio-Rad (Hercules, CA). Unless otherwise noted, all other chemicals and solvents were purchased from Sigma (St. Louis, MO).

\subsection{Insects}

Three populations of western corn rootworm beetles were used in these studies. Field populations were collected during late July and August of 1996 (500 per population) and were shipped to the USDA-ARS Northern Grain Insects Research Laboratory in
Brookings, SD, for maintenance and oviposition. Approximately 50000 eggs were obtained from each population and standard procedures were used to collect and maintain eggs until termination of diapause and to rear $F_{1}$ individuals to adults. ${ }^{13}$ Two additional generations were cultured, and $\mathrm{F}_{3}$ adults were shipped to the University of Nebraska, Lincoln, in the period January to March 1999. Unless noted, $\mathrm{F}_{3}$ adults were used in the experiments described below. Beetles were maintained at room temperature on a $14: 10 \mathrm{~h}$ (light:dark) photoperiod and provided with a diet of ground corn and bee pollen, with agar as a water source. The susceptible Saunders County (Nebraska) population was collected from an area with little exposure to adult management practices and no reports of control failures. The York and Phelps County (Nebraska) populations came from areas where adult management had been practiced for more than 10 years and where control failures and insecticide resistance are well documented. ${ }^{7-10}$ Resistance ratios originally identified for the York and Phelps populations (relative to Saunders) were c. 12- to 16fold, ${ }^{7}$ and the tolerance status of these populations has remained relatively constant during culture (Scharf et $a l^{10}$ and unpublished results).

\subsection{Bioassays}

Stock solutions $\left(10 \mathrm{mg} \mathrm{ml}^{-1}\right)$ of technical grade insecticides were prepared in acetone. Surface-residue bioassays took place within fipronil-coated, 20-ml borosilicate glass scintillation vials. ${ }^{8-10}$ Five fipronil concentrations were tested that resulted in 10-100\% mortality. Serial insecticide dilutions were made in $5-\mathrm{ml}$ volumes and individual vials received $0.5 \mathrm{ml}$ of insecticide dilution followed by continuous rolling in a fume hood until dry. Three replicates of 10 beetles were performed for each concentration and acetone control, and mortality was assessed as an inability of the beetles to respond to probing at $48 \mathrm{~h}$ posttreatment. Following treatment, beetles were held at $20-25^{\circ} \mathrm{C}$ in darkness without food or water. Mortality data were subjected to probit analysis to determine $\mathrm{LC}_{50}$ and $\mathrm{LC}_{90}$, and these values were statistically compared at the $95 \%$ level of confidence by the method of Robertson and Preisler. ${ }^{14}$

Topical application bioassays were performed as described previously, ${ }^{6}$ using the $\mathrm{F}_{2}$ generation Saunders and York populations. Insecticide dilutions $(0.5 \mu \mathrm{l})$ were applied to the dorsal abdomen of individual rootworm beetles and controls were treated with $0.5 \mu 1$ of acetone, or $\mathrm{PBO}$ in acetone for $\mathrm{PBO}$ bioassays. PBO assays were performed by treating beetles on the ventral thorax with PBO $(2.0 \mu \mathrm{g})$ in acetone, $1.0 \mathrm{~h}$ prior to fipronil treatment. Insecticidetreated beetles were held in Petri plates $(50 \times 9 \mathrm{~mm})$ at $20^{\circ} \mathrm{C}$ for $24 \mathrm{~h}$ in darkness. Mortality was assessed as an inability of the beetles to respond to probing. Topical bioassays consisted of three to five insecticide concentrations that caused mortality within the range 10 $100 \%$. Three replicates of 10 beetles were performed 
for each concentration and control to give total sample sizes of 120-180 beetles per treatment. Fifteen randomly selected beetles were weighed per treatment per day so that the dose could be calculated on a body weight basis (ng insecticide per mg body weight). Dose-mortality data were analyzed by the SAS PROBIT procedure (SAS Institute, Cary, NC). Significance of slope values was tested using POLO-PC software (LeOra, Berkeley, CA). Toxicity ratios (TR) evaluating synergism and relative sulfone toxicity were calculated for each treatment by dividing the $\mathrm{LD}_{50}$ and $\mathrm{LD}_{90}$ values for fipronil $+\mathrm{PBO}$ or the sulfone analog by the corresponding values for fipronil alone. Surfaceresidue resistance ratios (RR) were calculated by dividing $\mathrm{LD}_{50}$ and $\mathrm{LD}_{90}$ values of the York population by those of the Saunders population.

\subsection{In vivo metabolism and thin-layer chromatography}

Groups of 10 beetles from the three populations were topically treated with a sub-lethal dose of $\left[{ }^{14} \mathrm{C}\right]$ fipronil (65 ng, 532 DPM per insect) in acetone $(0.5 \mu \mathrm{l})$. Ten individuals were treated each time and held in $20-\mathrm{ml}$ glass scintillation vials for $0.5,1,2$, and $4 \mathrm{~h}$. The experiment was independently replicated three times. At each time-point, entire groups of 10 beetles were transferred to vials containing acetone $(3 \mathrm{ml})$. The beetles were gently swirled for $10 \mathrm{~s}$, and the acetone was decanted and transferred to a separate vial. The acetone was evaporated, and liquid scintillation fluid $(5 \mathrm{ml})$ was added for liquid scintillation counting and quantification of external radioactivity. The original holding vials were also liquid scintillation counted in a similar fashion to estimate excreted levels of radioactivity.

After rinsing with acetone as described above, groups of 10 beetles were homogenized in acetone ( $4 \mathrm{ml}$ ) using a rotor/strator-type of biohomogenizer (Biospec Products, Bartlettsville, OK). The vial and homogenizer were then rinsed with acetone $(3 \times 1 \mathrm{ml})$. The homogenate and rinsate were combined and centrifuged for $10 \mathrm{~min}$ at $3000 \mathrm{~g}$ and the supernatant decanted. The pellet was re-suspended in acetone $(2 \mathrm{ml})$, vortexed, centrifuged and the second supernatant was combined with the first. The remaining pellet was incubated for $72 \mathrm{~h}$ in Solvable ${ }^{\circledR}(1 \mathrm{ml}$; NEN Research Products, Boston, MA). Following a $5 \mathrm{~min}$ centrifugation at $3000 \mathrm{~g}$, unextractable internal radioactivity was determined by scintillation counting $100 \mu l$ of the supernatant.

Acetone supernatants were completely evaporated under nitrogen. Water $(1 \mathrm{ml})$ was added and extracted with ethyl acetate $(3 \times 2 \mathrm{ml})$. The ethyl acetate extracts were combined and received sodium sulfate (c10 mg). Aqueous and organic radioactive content (respectively) were determined by scintillation counting of $100 \mu \mathrm{l}$ of the remaining water and ethyl acetate extracts. To remove substances which were known to interfere with TLC, ethyl acetate was completely evaporated under nitrogen in a water bath. The remaining viscous residue received methanol $(100 \mu \mathrm{l})$, which was pipetted and transferred to a new vial after $5 \mathrm{~min}$. After evaporating to $c 20 \mu \mathrm{l}$ under nitrogen, the entire volumes of methanol were applied to pre-scored TLC plates (Whatman LK5DF, Clifton, $\mathrm{NJ}$ ) and developed for $30 \mathrm{~min}$ with dichloromethane + acetone + ethyl acetate $(95+3+2$ by volume). The TLC plates were dried and exposed to $x$-ray film (X-OMAT AR; Eastman Kodak, Rochester, NY) for 7 days at $-20^{\circ} \mathrm{C}$. Fipronil and the sulfone metabolites were identified by co-chromatography with nonradiolabeled standards and subsequent short-wave UV illumination. Identifiable radioactive zones were scraped from TLC plates and their radioactive content determined by liquid scintillation counting. Results were combined and transformed to percentages of total radioactivity per lane, and means for each TLC zone were analyzed using the Fisher LSD $(t)$ test.

\subsection{Protein preparations and assay}

Abdomens were dissected from frozen adult rootworms and homogenized with a Teflon glass PotterElvehjem type homogenizer in monobasic/dibasic $\mathrm{KPO}_{4}(150 \mathrm{~mm} ; \mathrm{pH} 7.4)$ containing glycerol $(100 \mathrm{ml}$ litre $\left.^{-1}\right)$, phenylmethylsulfonylfluoride ( $\left.1 \mathrm{mM}\right)$, phenylthiourea $(1 \mathrm{mM})$, ethylenediamine tetraacetate $(1 \mathrm{mM})$ and dithiothreitol $(0.1 \mathrm{~mm}){ }^{15}$ The homogenates were centrifuged at $10000 \mathrm{~g}$ for $10 \mathrm{~min}$ at $4{ }^{\circ} \mathrm{C}$ in a microcentrifuge, and the supernatant was filtered through glass wool. The $10000 \mathrm{~g}$ supernatant was ultracentrifuged at $350000 \mathrm{~g}$ for $60 \mathrm{~min}$, and the resulting microsomal pellet re-suspended in homogenization buffer containing glycerol $\left(200 \mathrm{ml} \mathrm{litre}^{-1}\right)$. Protein concentration for all preparations was determined with a commercially available bicinchoninic acid protein assay (Pierce, Rockford, IL) according to the manufacturer's instructions, using bovine serum albumin as the standard.

\subsection{In vitro metabolism}

Metabolism of $\left[{ }^{14} \mathrm{C}\right]$ fipronil was studied in vitro using cytosolic and microsomal subcellular protein fractions, prepared as described in Section 2.5 from dissected corn rootworm abdomens. NADPH and reduced glutathione (GSH) were used as cofactors in microsomal and cytosolic reactions (respectively) to identify the involvement of the cytochrome P450 and glutathione- $S$-transferase enzyme systems. Individual reactions $(0.31 \mathrm{ml})$ contained protein $(0.5 \mathrm{mg})$, NADPH (1 mM) or reduced glutathione $(5.5 \mathrm{~mm})$, $5500 \mathrm{DPM}\left[{ }^{14} \mathrm{C}\right]$ fipronil, and a remaining volume of Tris- $\mathrm{HCl}(0.4 \mathrm{M}, \mathrm{pH} 7.5)$. For PBO-inhibited reactions, PBO in ethanol $(5 \mu \mathrm{l} ; 10 \mathrm{~mm})$ was added $5 \mathrm{~min}$ in advance of substrate, which provided a final concentration of $170 \mu \mathrm{M}$ PBO. Duplicate reactions were performed without NADPH or GSH and, in control reactions, protein was substituted by $50 \mu \mathrm{l}$ of homogenization buffer. Reactions were initiated by the addition of substrate, proceeded for $1 \mathrm{~h}$ at $30^{\circ} \mathrm{C}$, and were terminated by partitioning with ethyl acetate 
$(3 \times 1 \mathrm{ml})$. The entire remaining aqueous phase $(0.3 \mathrm{ml})$ and a portion $(0.1 \mathrm{ml})$ of the combined ethyl acetate extracts were scintillation counted to determine the proportion of radioactivity partitioning between the aqueous and organic phases. The ethyl acetate extracts were dried over anhydrous sodium sulfate and completely evaporated under nitrogen. The remaining residue was re-dissolved in $15 \mu \mathrm{l}$ methanol and the entire volume applied to TLC plates. The plates were developed, and the radioactivity contained in various TLC zones quantified as described in Section 2.4. Results for control reactions were determined and used to correct for nonenzymatic degradation of fipronil, and the entire experiment was independently replicated three times.

\subsection{Glutathione-S-transferase studies}

Glutathione-S-transferase (GST)-based metabolism of fipronil was studied using GST enzyme purified from the York population. GST was purified using pre-packed glutathione agarose affinity columns (Sigma), and three separate purifications were performed. Crude cytosolic proteins were isolated from rootworm abdomens as described above, using Tris $(0.4 \mathrm{M})$ and EDTA $(0.001 \mathrm{M} ; \mathrm{pH} 7.5)$ as the homogenization buffer. For chromatography, a Bio-Rad Econo-FPLC chromatography system (Hercules, CA) was used to collect $1-\mathrm{ml}$ fractions. Columns were equilibrated with Tris-EDTA before cytosolic protein (c4 mg) was loaded at a flow rate of $0.2 \mathrm{mlmin}^{-1}$. At a flow rate of $0.5 \mathrm{ml} \mathrm{min} \mathrm{m}^{-1}$, non-retained proteins were washed off the column in $c 7 \mathrm{ml}$ equilibration buffer (see Fig 3 A). GST was eluted in equilibration buffer containing reduced glutathione $(5 \mathrm{~mm})$. The identity of and purity of GST proteins was confirmed by monitoring 1chloro-3,4-dinitrobenzene (CDNB; Aldrich, Milwaukee, WI) activity and by silver staining of $12 \%$ SDSPAGE gels. Fractions having a high CDNB activity were pooled and concentrated at $4^{\circ} \mathrm{C}$ using a $10 \mathrm{kDa}$ cutoff Microsep centrifugal concentrator (Gelman, Ann Arbor, MI).

CDNB activity was monitored using a microplate reader (Bio-Tek Instruments, Winooski, VT), by measuring the change in absorbance at $340 \mathrm{~nm}$ for 2 min. ${ }^{16}$ The path length was $0.8 \mathrm{~cm}$ and an extinction coefficient of $9.5 \mathrm{mM}^{-1} \mathrm{~cm}^{-1}$ was used to calculate specific activity. Non-enzymatic control reactions contained all reaction components except protein. In vitro metabolism of $\left[{ }^{14} \mathrm{C}\right]$ fipronil by GST was studied using $c 0.01 \mathrm{mg}$ purified protein per reaction. Three replicate reactions (each) contained protein, reduced glutathione $(5.5 \mathrm{mM})$, and $5500 \mathrm{DPM}$ of the radiolabeled substrate in a total volume of $305 \mu \mathrm{l}$. Reaction times were $30 \mathrm{~min}$ and duplicate blank reactions were performed without protein. Reactions were terminated, subjected to chromatography, and results quantified as described above in Section 2.6.

\section{RESULTS}

\subsection{Bioassays}

Surface-residue bioassays were used to compare the responses of the three laboratory-reared $\mathrm{F}_{3}$ generations of field-collected populations (Fig 1). Based on the overlap of probit mortality lines and raw percentage mortality points, the three populations can be considered equally susceptible to fipronil at $48 \mathrm{~h}$ posttreatment by this exposure method. The $\mathrm{LC}_{50}$ and $\mathrm{LC}_{90}$ estimates for the probit lines indicate some heterogeneity among the populations, although no significant differences existed $(P \leq 0.05)$.

Topical toxicity bioassays were used to examine the relative toxicity of fipronil, fipronil + monooxygenase inhibitor PBO and the oxidative sulfone metabolite (Table 1) to the $\mathrm{F}_{2}$ generations. Fipronil and fipronilsulfone were of comparable toxicity to the York and the Saunders populations, which is emphasized by the overlap of fiducial limits at $\mathrm{LD}_{50}$ and $\mathrm{LD}_{90}$ for the two analogs. Resistance ratios at $\mathrm{LD}_{50}$ and $\mathrm{LD}_{90}$ for both fipronil $\left(\mathrm{RR}_{50}=0.86, \mathrm{RR}_{90}=0.61\right)$ and fipronil-sulfone $\left(R R_{50}=0.64, R_{90}=0.77\right)$ show a non-significant trend toward greater susceptibility in the York population. For both populations, application of PBO $1 \mathrm{~h}$ prior to fipronil resulted in slight, although not significant antagonism. Specifically, PBO had effects on the slopes of probit mortality lines, which
Figure 1. Fipronil probit-mortality plots and lethal concentration estimates for three western corn rootworm populations (Saunders, York and Phelps), obtained using surfaceresidue (vial) bioassays. Lines were obtained by probit analysis of crude percentage mortality data (individual points). Shown in inset table are $\mathrm{LC}_{50}$ and $\mathrm{LC}_{90}$ estimates for each population. LC values at each level of probit mortality are not significantly different (ie followed by the same letter) by the method of Robertson and Preisler. $^{14}$

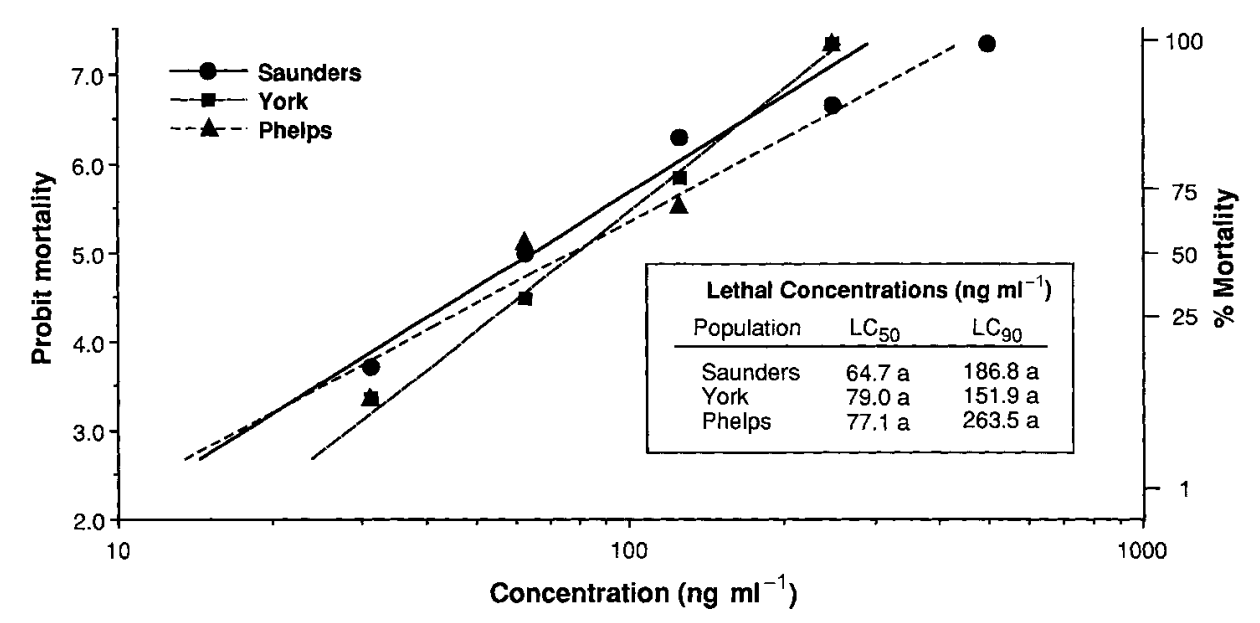

Pest Manag Sci 56:757-766 (2000) 
Table 1. Toxicity of fipronil, fipronil + PBO, and fipronil-sulfone to insecticide-susceptible and -resistant western corn rootworm populations, as determined by topical application bioassays

\begin{tabular}{|c|c|c|c|c|c|c|c|c|c|c|}
\hline Population $^{a}$ & Treatment & $n$ & Slope $(S E)^{\mathrm{b}}$ & $\chi^{2 c}$ & $L D_{50}(95 \% C l)^{d}$ & $T R_{50}{ }^{e}$ & $R R_{50}{ }^{\mathrm{f}}$ & $L D_{90}(95 \% C l)^{d}$ & $T R_{90}{ }^{e}$ & $R R_{90}{ }^{\dagger}$ \\
\hline \multirow[t]{3}{*}{ Saunders } & Fipronil & 150 & $1.97(0.31) b$ & 4.5 & $0.07(0.05-0.10)$ & - & - & $0.33(0.22-0.67)$ & - & - \\
\hline & Fipronil+PBO & 180 & $1.51(0.24) a$ & 0.7 & $0.06(0.04-0.08)$ & 0.86 & - & $0.42(0.26-0.93)$ & 1.27 & - \\
\hline & Fipronil-sulfone & 120 & $4.02(0.07) \mathrm{c}$ & 0.1 & $0.11(0.09-0.13)$ & 1.57 & - & $0.22(0.17-0.36)$ & 0.67 & - \\
\hline \multirow[t]{3}{*}{ York } & Fipronil & 150 & $2.47(0.40) b$ & 0.3 & $0.06(0.05-0.08)$ & - & 0.86 & $0.20(0.14-0.37)$ & - & 0.61 \\
\hline & Fipronil + PBO & 180 & $1.50(0.23) a$ & 0.7 & $0.06(0.04-0.09)$ & 1.00 & 1.00 & $0.45(0.28-0.99)$ & 2.25 & 1.07 \\
\hline & Fipronil-sulfone & 120 & $2.47(0.42) b$ & 3.9 & 0.07 (0.05-0.09) & 1.17 & 0.64 & $0.17(0.15-0.42)$ & 0.85 & 0.77 \\
\hline
\end{tabular}

a Western corn rootworm populations: Saunders (susceptible to organophosphate and carbamate insecticides), York (resistant to organophosphate and

carbamate insecticides). Data shown for the Saunders population is taken from Scharf and Siegfried. ${ }^{6}$

${ }^{b}$ Values followed by the same letter are not significantly different $(P \leqslant 0.05)$ as determined using POLO-PC software.

${ }^{c}$ Pearson Chi-Square test, indicating the goodness-of-fit of crude mortality data. All $P$ values are acceptable.

${ }^{d}$ Lethal doses of insecticide in $\mathrm{ng}$ toxicant per mg of body weight at the $\mathrm{LD}_{50}$ and $\mathrm{LD}_{90}$ levels of probit mortality (with $95 \%$ confidence intervals). Average weights $( \pm S D)$ were $9.5( \pm 4.4)$ (Saunders) and $9.5( \pm 2.8)$ (York).

e Toxicity ratios (calculated separately for each population) indicating the fold-difference for fipronil + PBO or sulfone metabolite in relation to fipronil alone at the $\mathrm{LD}_{50}$ and $L D_{90}$.

${ }^{f}$ Resistance ratios calculated by dividing the $L D_{50}$ and $L D_{90}$ values of the York population by those from the Saunders population.

$\mathrm{PBO}=$ piperonyl butoxide.

became significantly lower in its presence. This change in slope resulted in marginal to no effects on $\mathrm{LD}_{50}$, but suggested slight antagonism of toxicity at $\mathrm{LC}_{90}$.

\subsection{In vivo metabolism}

Following in vivo topical treatment of $\left[{ }^{14} \mathrm{C}\right]$ fipronil, the percentage distribution of radioactivity among various fractions and percentage recovery were quantified for the three field-collected populations (Table 2). A sub-lethal dose of $532 \mathrm{DPM}(65 \mathrm{ng})\left[{ }^{14} \mathrm{C}\right]$ fipronil per beetle was used. This dose did not induce mortality, but was associated with mild poisoning symptoms $3 \mathrm{~h}$ after treatment. Through $4 \mathrm{~h}$, no notable differences were identified between populations in external (ie penetration), excreted and internal organo-soluble radioactivity. However, differences did occur in internal aqueous and unextractable internal radioactivity, with the Saunders population having higher percentages at later time-points. The percentage recovery of radioactivity was estimated to be slightly above $100 \%$ at all time-points for all populations.

Internal organic extracts of homogenized beetles from the three populations were subjected to TLC and results are shown in Fig 2. Autoradiograms of developed TLC plates identified radioactivity in only three zones $\left[R_{\mathrm{f}}=0.0\right.$ (origin), $R_{\mathrm{f}}=0.8$ (fipronil), and $R_{\mathrm{f}}=0.9$ (fipronil-sulfone)]. The sulfide metabolite, which migrates with the solvent front $\left(R_{\mathrm{f}}=1.0\right)$, was not identified. Patterns of fipronil disappearance and sulfone formation were similar between the three study populations, although significantly more fipronil and less sulfone were present in the Phelps population at $0.5,1$ and $2 \mathrm{~h}(P \leq 0.05)$. Of most interest is that the sulfone levels increased throughout the study period and, by $4 \mathrm{~h}$ post-treatment, sulfone quantities were greatest in the York and Saunders populations $(P \leq 0.05)$. Immobile polar material at the origin was significantly greater $(P \leq 0.05)$ for the York and Phelps populations.

\subsection{In vitro metabolism by sub-cellular fractions}

Results of in vitro metabolism studies by sub-cellular (ie microsomal and cytosolic) protein fractions are shown in Table 3. Sulfone formation was both $\mathrm{NADPH}$-dependent and inhibited by $\mathrm{PBO}$ in microsomal preparations, confirming that sulfone formation is catalyzed by cytochrome P450 monooxygenase(s). Greater quantities of sulfone were formed in microsomes from the resistant York and Phelps populations, although some sulfone metabolite was formed in the absence of NADPH. No immobile polar materials were detectable at the origin in any microsomal reactions. These immobile materials were readily detectable in cytosolic reactions, and were elevated in reactions which contained glutathione. Fipronil-sulfone was not observed in any cytosolic reactions except in the York population in the presence of glutathione; however, this occurrence may be related to non-enzymatic/experimental processes.

\subsection{In vitro metabolism by glutathione-S- transferase}

For the York population, the preceding experiments indicated greater ${ }^{14} \mathrm{C}$-labeled polar metabolite formation in vivo (Fig 2) and in vitro (Table 3), and greater glutathione-dependent activity in vitro toward the model substrate DCNB (Table 4). Therefore GSTdependent metabolism of $\left[{ }^{14} \mathrm{C}\right]$ fipronil was studied using GST enzyme purified from the York population. Figure 3 A shows a typical glutathione-agarose chromatogram for the GST purifications achieved in the study. The protein was purified to apparent homogeneity in one step, based on the presence of a single $27 \mathrm{kDa}$ protein in fractions of highest CDNB activity (as visualized on silver-stained, 12\% SDSPAGE gels; Fig 3 B). The $27 \mathrm{kDa}$ protein appeared in crude protein extracts and purified fractions, but not in column flow-through (Fig $3 \mathrm{~B}$ ). Three purifications from $c 11.5 \mathrm{mg}$ starting material were performed and 


\begin{tabular}{|c|c|c|c|c|}
\hline \multirow[b]{2}{*}{ Population } & \multicolumn{4}{|c|}{ Radioactivity (\%) $\left( \pm\right.$ SEM) ${ }^{a}$} \\
\hline & $0.5 h$ & $1 h$ & $2 h$ & $4 h$ \\
\hline \multicolumn{5}{|c|}{ External radioactivity ${ }^{\mathrm{b}}$} \\
\hline Saunders & $58.0( \pm 4.0)$ & $42.6( \pm 3.6)$ & $22.9( \pm 5.8)$ & $12.1( \pm 1.5)$ \\
\hline York & $58.7( \pm 5.9)$ & $45.1( \pm 3.1)$ & $27.5( \pm 0.8)$ & $10.6( \pm 1.3)$ \\
\hline Phelps & $53.4( \pm 0.8)$ & $36.7( \pm 2.1)$ & $24.7( \pm 1.4)$ & $17.5( \pm 3.2)$ \\
\hline \multicolumn{5}{|c|}{ Excreted radioactivity $^{\mathrm{C}}$} \\
\hline Saunders & $3.7( \pm 1.3)$ & $4.2( \pm 1.1)$ & $5.5( \pm 1.7)$ & $6.4( \pm 1.0)$ \\
\hline York & $1.6( \pm 0.1)$ & $3.6( \pm 0.4)$ & $4.3( \pm 0.5)$ & $7.9( \pm 2.2)$ \\
\hline Phelps & $2.7( \pm 0.3)$ & $3.5( \pm 0.4)$ & $5.0( \pm 1.4)$ & $7.8( \pm 1.9)$ \\
\hline \multicolumn{5}{|c|}{ Internal organosoluble radioactivity ${ }^{d}$} \\
\hline Saunders & $34.9( \pm 5.3)$ & $46.7( \pm 3.4)$ & $62.2( \pm 8.4)$ & $72.0( \pm 1.7)$ \\
\hline York & $35.2( \pm 7.3)$ & $46.6( \pm 2.9)$ & $62.2( \pm 1.0)$ & $72.9( \pm 3.0)$ \\
\hline Phelps & $39.4( \pm 1.2)$ & $56.2( \pm 1.4)$ & $66.0( \pm 3.7)$ & $67.9( \pm 4.1)$ \\
\hline \multicolumn{5}{|c|}{ Internal aqueous radioactivity ${ }^{\mathrm{e}}$} \\
\hline Saunders & $0.4( \pm 0.2)$ & $1.2( \pm 0.8)$ & $2.7( \pm 0.6)$ & $3.7( \pm 0.8)$ \\
\hline York & $0.2( \pm 0.2)$ & $0.3( \pm 0.2)$ & $1.9( \pm 1.1)$ & $2.0( \pm 1.0)$ \\
\hline Phelps & $0.3( \pm 0.3)$ & $0.8( \pm 0.4)$ & $0.7( \pm 0.3)$ & $1.1( \pm 0.9)$ \\
\hline \multicolumn{5}{|c|}{ Unextractable internal radioactivity ${ }^{\dagger}$} \\
\hline Saunders & $3.1( \pm 0.5)$ & $5.3( \pm 1.1)$ & $6.7( \pm 1.2)$ & $5.9( \pm 1.2)$ \\
\hline York & $4.3( \pm 1.4)$ & $4.4( \pm 0.5)$ & $4.0( \pm 0.2)$ & $6.5( \pm 0.6)$ \\
\hline Phelps & $4.2( \pm 0.9)$ & $2.8( \pm 0.7)$ & $3.6( \pm 1.0)$ & $5.8( \pm 0.7)$ \\
\hline \multicolumn{5}{|c|}{ Percentage recovery of radioactivity ${ }^{g}$} \\
\hline Saunders & $120.8( \pm 7.3)$ & $117.6( \pm 2.7)$ & $104.8( \pm 15.0)$ & $111.7( \pm 14.3)$ \\
\hline York & $128.6( \pm 8.7)$ & $109.1( \pm 2.3)$ & $112.9( \pm 6.6)$ & $130.0( \pm 4.9)$ \\
\hline Phelps & $129.8( \pm 7.5)$ & $139.1( \pm 4.6)$ & $147.5( \pm 7.5)$ & $114.7( \pm 6.7)$ \\
\hline
\end{tabular}

Table 2. Distribution and recovery of radioactivity following topical treatment with $\left[{ }^{14} \mathrm{C}\right]$ fipronil for insecticide-resistant and susceptible western corn rootworm populations

\footnotetext{
a Ten insects were treated with 5320 DPM $\left[{ }^{14} \mathrm{C}\right]$ fipronil per time period per population, and the entire experiment was replicated three times.

${ }^{\mathrm{b}}$ Radioactivity present in acetone rinses of insects.

${ }^{c}$ Radioactivity remaining in holding vials.

${ }^{\mathrm{d}}$ Organosoluble radioactivity present in ethyl acetate phase after partitioning between ethyl acetate and water.

${ }^{\text {e }}$ Aqueous radioactivity present in water phase after partitioning between ethyl acetate and water.

${ }^{f}$ Radioactivity remaining in tissue pellets.

${ }^{g}$ Percentage recovery of radioactivity based on the theoretical application of 5320 DPM per replicate per time period.
}

yielded $0.07 \mathrm{mg}$ of purified and concentrated GST. The purification factor was 100.6 -fold with $61.0 \%$ recovery, as calculated from the specific activities of 30.5 and $3066.9 \mu \mathrm{mol} \mathrm{min}^{-1} \mathrm{mg}^{-1}$ before and after purification, respectively.

In vitro metabolism of $\left[{ }^{14} \mathrm{C}\right]$ fipronil was examined using $0.01 \mathrm{mg}$ purified GST enzyme per assay, and 30-min reaction times (Fig $3 \mathrm{C}$ ). Three polar metabolites were identified which were not previously detectable in in vitro studies involving crude cytosolic preparations. These metabolites of $R_{\mathrm{f}}=0.21,0.31$ and 0.35 comprised $32.5 \%$ of total radioactivity, and are unlikely to be conjugates of de-halogenated fipronil and glutathione. In addition, immobile polar material at the origin and unmetabolized fipronil comprised $10.2 \%$ and $57.3 \%$, respectively, of total radioactivity. These percentages of radioactivity contained in unmetabolized fipronil and at the origin are reduced and increased (respectively) in relation to in vitro metabolism results for crude, cytosolic protein preparations (Table 3).

\section{DISCUSSION}

\subsection{Bioassays, toxicity and resistance management}

Relative to the susceptible Saunders population, the insecticide resistant rootworm populations used in this study exhibit significantly greater tolerance to a number of neurotoxic insecticide classes. ${ }^{7-10}$ In addition, one of the populations possesses elevated NADPH-dependent mono-oxygenase activity toward model substrates ${ }^{8}$ and the insecticide carbaryl. ${ }^{10}$ It is primarily for these reasons, alongside the observations of other researchers that mono-oxygenase inhibitors antagonize fipronil toxicity (eg Valles $e \mathrm{al}^{2}$ ), that it was initially suggested that enhanced oxidative activity might lead to greater fipronil susceptibility in some insecticide-resistant insect populations. ${ }^{6}$ In the western corn rootworm populations studied here, there was no significant effect of PBO on fipronil toxicity. However, in topical bioassays the sulfone metabolite induced nearly identical toxicity to the parent compound, fipronil. In addition, the sulfone 

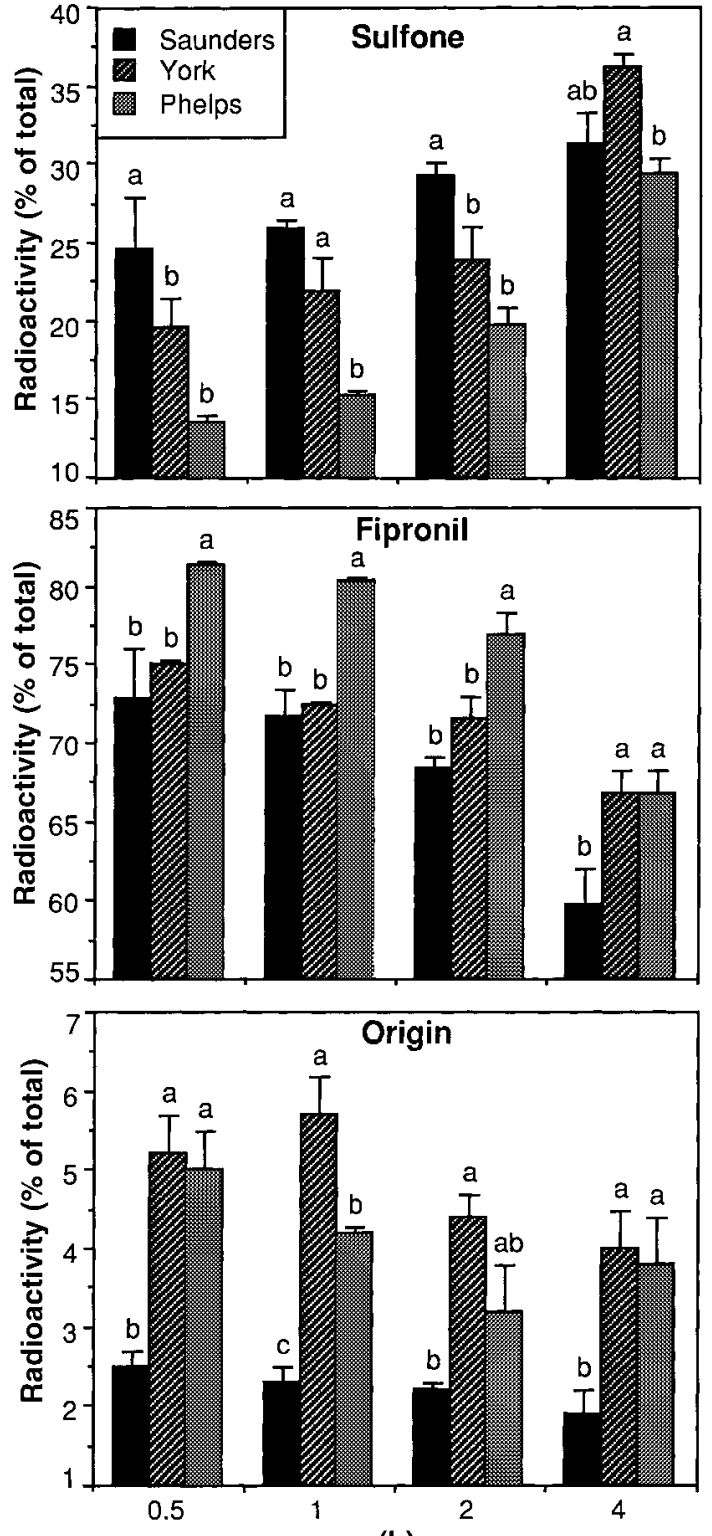

(h)

Figure 2. Percentage distribution of radioactivity among three TLC zones (Sulfone, Fipronil and Origin) following in vivo treatment of 3 rootworm populations (Saunders, York and Phelps) with $\left[{ }^{14} \mathrm{C}\right]$ fipronil. Within each time period for each TLC zone, means with the same letter are not significantly different by the Fisher LSD $t$ test $(P \leq 0.05, n=3)$.

metabolite is also now known to induce nearly identical neurophysiological effects to fipronil,${ }^{6}$ which may explain the lack of effect observed with PBO. Nonetheless, these data indicate that fipronil could be implemented effectively as a management strategy in areas where rootworm resistance to organophosphate and carbamate insecticides has been identified.

\subsection{Fipronil metabolism and the importance of sulfone formation}

Consistent trends in metabolite formation were identified between in vivo and vitro studies, and results were used to formulate potential pathways for fipronil metabolism in the western corn rootworm (Fig 4). Results indicate that fipronil metabolism is occurring in both microsomal and cytosolic sub-cellular fractions. The two general conversions identified were oxidation of the thioether constituent (ie sulfone formation) and dehalogenization with possible conjugation to glutathione (several sites). In vitro studies demonstrated that sulfone formation is an oxidative process mediated by cytochrome $\mathrm{P} 450$ monooxygenases. The three observations which support this conclusion are that sulfone formation: (1) appears to exclusively occur in microsomes, (2) is NADPHdependent, and (3) is inhibited by the monooxygenase inhibitor PBO.

Thioether-containing insecticides from nearly every neurotoxic insecticide class have been found to be oxidatively modified to sulfone metabolites (see Matsumura ${ }^{17}$ ). In many cases, sulfone metabolites of these insecticides retain toxic effects. As such, it is not surprising that the phenylpyrazoles exhibit similar toxicological characteristics to other thioether insecticides from diverse insecticide classes. The only previous study of fipronil metabolism in insects identified both sulfone and sulfide metabolites in internal extracts from Spodoptera eridanea orally dosed with $\left[{ }^{14} \mathrm{C}\right]$ fipronil, although the dominant metabolite present was the sulfone analog. ${ }^{5}$ Based on cochromatography with non-radiolabeled standards, the only thioether modification observed in the present study was oxidation to fipronil-sulfone. These differing outcomes from two insect groups suggest that differences in phenylpyrazole toxicology and pharmacokinetics exist among insect species. Such differences will probably prohibit the use of generalized statements regarding the processes involved in fipronil metabolism. However, as identified here, the formation of a toxic sulfone metabolite offers explanation for the high level of fipronil toxicity to insects in general.

Fipronil dehalogenization appears to be mediated by cytosolic glutathione- $S$-transferase (GST), as suggested by in vitro studies of $\left[{ }^{14} \mathrm{C}\right]$ fipronil metabolism. Specific findings in support of this conclusion are the glutathione-dependence of immobile polar metabolite formation in the cytosol, and formation of unique polar metabolites/conjugates following incubation with purified GST. Results also suggest that dehalogenization occurs to both the parent material and the sulfone metabolite, although specific modifications remain unclear. Insect GSTs are well-known for their involvement in dehalogenization, DDT dehydrochlorination being the best-known example. ${ }^{17,18}$ However, the fipronil molecule is substituted with both chlorine and trifluoromethyl moieities (two sites each). Three polar metabolites/conjugates were observed in addition to immobile polar material at the origin in metabolism experiments involving purified GST. These mobile metabolites were not visible in incubations with crude cytosolic protein extracts which included identical substrate concentrations. Whether these metabolites are glutathione conjugates or non-conjugated polar metabolites remains unknown; however, the fact that they possess mobility 
Table 3. In vitro metabolism of $\left[{ }^{14} \mathrm{C}\right]$ fipronil by subcellular fractions of organophosphate-resistant and susceptible western corn rootworm populations

\begin{tabular}{|c|c|c|c|c|}
\hline \multirow[b]{2}{*}{$\begin{array}{l}\text { Fraction } \\
\text { population }\end{array}$} & \multirow[b]{2}{*}{ Reaction conditions $^{\mathrm{b}}$} & \multicolumn{3}{|c|}{$\begin{array}{c}\text { Organo-soluble radioactivity on developed TLC } \\
\text { plates }(\%)( \pm S E M)^{\mathrm{a}}\end{array}$} \\
\hline & & $\begin{array}{l}\text { Origin } \\
(R f=0.0)\end{array}$ & $\begin{array}{l}\text { Fipronil } \\
(R f=0.8)\end{array}$ & $\begin{array}{l}\text { Fipronil-sulfone } \\
\qquad(R f=0.9)\end{array}$ \\
\hline \multicolumn{5}{|c|}{$350000 \mathrm{~g}$ pellet (microsomal fraction) } \\
\hline \multirow[t]{4}{*}{ Saunders } & No NADPH & $N D^{c}$ & 100 & ND \\
\hline & $+\mathrm{NADPH}$ & ND & $96.2( \pm 8.2)$ & $3.2( \pm 1.1)$ \\
\hline & No NADPH + PBO & ND & 100 & ND \\
\hline & + NADPH + PBO & ND & 100 & ND \\
\hline \multirow[t]{4}{*}{ York } & No NADPH & ND & $95.9( \pm 4.3)$ & $3.4( \pm 0.6)$ \\
\hline & $+\mathrm{NADPH}$ & ND & $92.9( \pm 0.1)$ & $7.9( \pm 3.0)$ \\
\hline & No NADPH + PBO & ND & 100 & ND \\
\hline & + NADPH+PBO & ND & 100 & ND \\
\hline \multirow[t]{4}{*}{ Phelps } & No NADPH & ND & $96.5( \pm 6.8)$ & $2.9( \pm 0.8)$ \\
\hline & $+\mathrm{NADPH}$ & ND & $94.7( \pm 8.2)$ & $5.9( \pm 1.9)$ \\
\hline & No NADPH + PBO & ND & 100 & ND \\
\hline & + NADPH+PBO & ND & 100 & ND \\
\hline \multicolumn{5}{|c|}{$350000 \mathrm{~g}$ supernatant (cytosolic fraction) } \\
\hline \multirow[t]{2}{*}{ Saunders } & No GSH & $3.6( \pm 1.8)$ & $96.5( \pm 8.8)$ & ND \\
\hline & $+\mathrm{GSH}$ & $4.4( \pm 2.0)$ & $94.8( \pm 10.4)$ & ND \\
\hline \multirow[t]{2}{*}{ York } & No GSH & $4.3( \pm 2.8)$ & $97.8( \pm 10.3)$ & ND \\
\hline & $+\mathrm{GSH}$ & $5.9( \pm 1.6)$ & $85.6( \pm 6.1)$ & $6.1( \pm 0.9)$ \\
\hline \multirow[t]{2}{*}{ Phelps } & No GSH & $4.0( \pm 1.9)$ & $97.8( \pm 9.6)$ & ND \\
\hline & $+\mathrm{GSH}$ & $4.4( \pm 2.2)$ & $97.0( \pm 7.9)$ & ND \\
\hline
\end{tabular}

in an organic solvent system suggests they are not glutathione conjugates.

\subsection{Conclusions}

This study represents the first effort to characterize enzyme systems involved in fipronil metabolism and sulfone formation by a combined in vivo and in vitro approach. Unique challenges were posed by the relatively high toxicity of fipronil, ${ }^{1}$ which made difficult the identification of a sub-lethal dose of radiolabeled material that would permit detection of internal organo-soluble metabolites while minimizing mortality in vivo. Preliminary studies (results not

Table 4. Glutathione-S-transferase dependent metabolism of the model substrate DCNB by western corn rootworm populations

\begin{tabular}{|c|c|c|}
\hline Population & $\mathrm{GSH}^{\mathrm{a}}$ & $\begin{array}{c}\text { Mean activity ( } \mu \text { mol } \min ^{-1} \mathrm{mg}^{-1} \text { protein) } \\
( \pm S E M)^{\mathrm{b}}\end{array}$ \\
\hline \multirow[t]{2}{*}{ York } & - & 0.0 \\
\hline & + & $30.5( \pm 1.4) a$ \\
\hline \multirow[t]{2}{*}{ Phelps } & - & 0.0 \\
\hline & + & $22.3( \pm 0.3) b$ \\
\hline \multirow[t]{2}{*}{ Saunders } & - & 0.0 \\
\hline & + & $16.5( \pm 0.6) c$ \\
\hline $\begin{array}{l}\text { a Reduced gl } \\
\text { of } 5.5 \mathrm{~mm} \text {. } \\
{ }^{\mathrm{b}} \text { Results of th } \\
\text { on three sepa }\end{array}$ & $\begin{array}{l}\text { athione }(C \\
\text { te days ( }\end{array}$ & $\begin{array}{l}\text { ASH) was used as a cofactor at a final concentration } \\
n=9 \text { ). Means ( } \pm \text { SE) followed by different letters are } \\
\text { the Fisher LSD test }(P \leq 0.01) \text {. }\end{array}$ \\
\hline
\end{tabular}

shown) using a dose of $11 \mathrm{ng}$ (90 DPM) $\left[{ }^{14} \mathrm{C}\right]$ fipronil clearly showed the sulfone metabolite to be the dominant toxic analog by $24 \mathrm{~h}$ post-treatment. However, because of the low levels of radiolabel present, this dose did not allow the detection of polar metabolites. It is primarily for this reason that a higher $\left[{ }^{14} \mathrm{C}\right]$ fipronil dose (65 ng, $\left.532 \mathrm{DPM}\right)$ was utilized in the reported in vivo studies. This higher dose induced mortality by $6-10 \mathrm{~h}$ post-treatment which necessitated shorter exposure periods (ie 0.5, 1, 2 and $4 \mathrm{~h}$ ). However, in vivo data, in combination with in vitro studies using both crude sub-cellular protein fractions and purified glutathione- $S$-transferase, clearly show the dual importance of oxidative sulfone formation by cytochrome P450 and potential dehalogenization by glutathione- $S$-transferase.

This study examined an important economic pest of US agriculture, rather than a model laboratory insect. The utilization of other more tolerant model insect species could assist future efforts to characterize these systems. Nevertheless, this research has impacts on both basic insecticide toxicology and insecticide resistance management. Of primary importance, as described above, is the documentation that a neurotoxic, oxidative sulfone metabolite is formed which retains essentially all the toxicity of its parent compound. The documentation of this phenomenon helps to explain the relatively high toxicity of fipronil and why, in numerous insect groups, fipronil typically retains its toxicity to populations which do not appear 
Figure 3. (A) Elution profile for glutathione$S$-transferase (GST) purification by glutathione-agarose chromatography. Absorbance change and absorbance, respectively, following incubation with DCNB (left axis) and incubation with BCA protein reagents (right axis), for fractionated column eluate ( $x$-axis). Arrow indicates the introduction of $5 \mathrm{~mm}$ reduced glutathione (GSH) to chromatography columns (see Section 2.7 for details). (B) Silver-stained SDS-PAGE gel showing crude cytosolic proteins $(350000 \mathrm{~g}$ supernatant), column flow-through (nonretained proteins), molecular weight markers (not shown for clarity), and purified GST proteins. Arrowhead indicates position of GST protein. (C) Percentage distribution of radioactivity following TLC separation of organosoluble extracts from incubations of purified GST with $\left[{ }^{14} \mathrm{C}\right]$ fipronil. Four TLC zones (sulfone, fipronil, polar metabolites and origin) were evaluated.

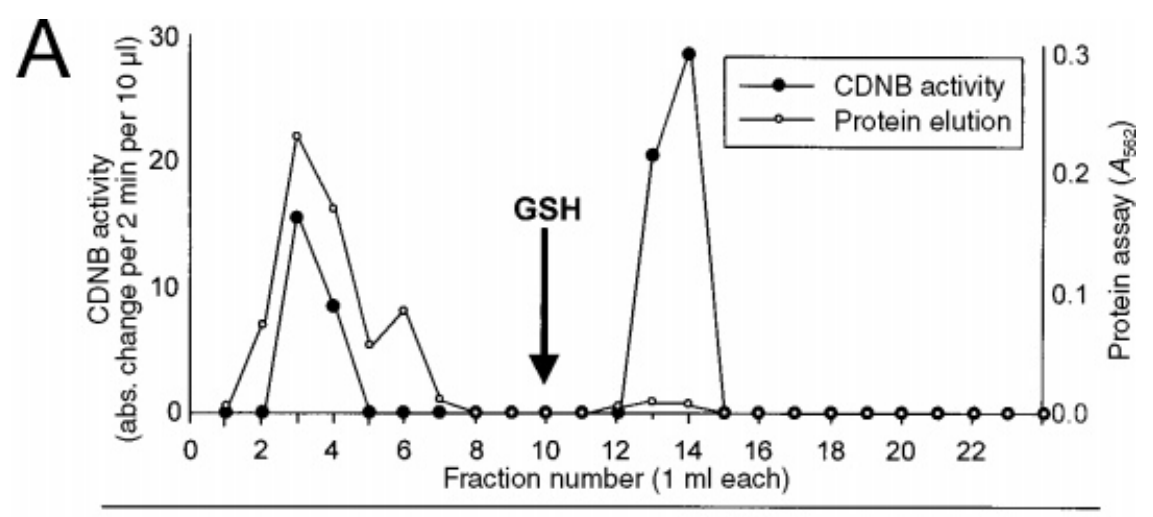

B

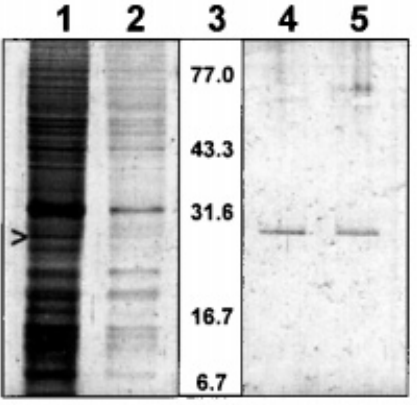

$1=350000 \mathrm{~g}$ supernatant

2 = Non-retained proteins (fraction no. 3 ) 3 = Molecular weight markers (kDa)

4 = Pure GST (fraction no. 13)

5 = Pure GST (fraction no. 14)

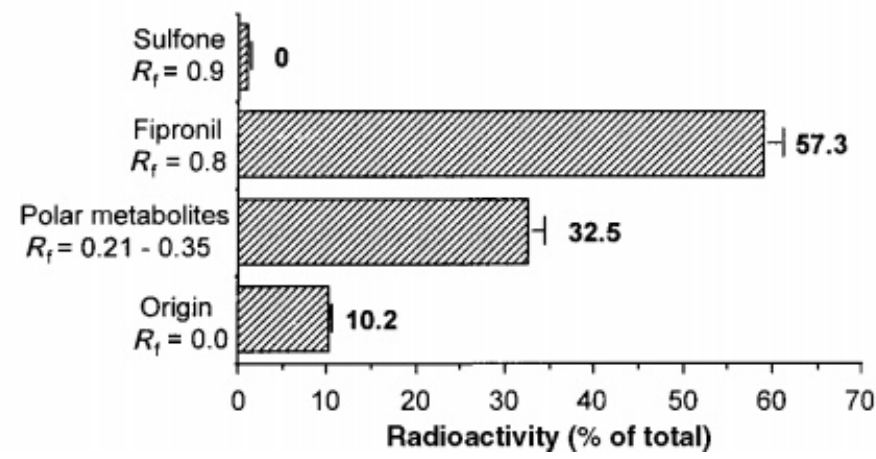<smiles>C[As](=O)c1c(C#N)nn(-c2c(Cl)cc(C(F)(F)F)cc2Cl)c1N</smiles>

FIPRONIL. GST<smiles>[X]c1cc([X])c(-n2nc(N)c([Sb](=O)O)c2N)c([X])c1</smiles>

POLAR METABOLITES AND / OP CONJUGATES

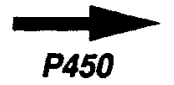<smiles>C[As](=O)(O)c1c(C#N)nn(-c2c(Cl)cc(C(F)(F)F)cc2Cl)c1N</smiles>
SULFONE GST<smiles>[X]c1cc(C#N)cc([X])c1-n1nc(C)c(S([X])(=O)=O)c1N</smiles>

POLAR METABOLITES AND / OR CONJUGATES 
to be in possession of altered GABA-gated chloride/ ionopore target sites. ${ }^{2-4,19,20}$ The similar toxicity of fipronil and fipronil-sulfone observed here also helps to explain the apparent lack of effects by $\mathrm{PBO}$ in bioassays (ie by inhibiting sulfone formation the net toxicity is not compromised). More general speculation of this relationship on a broad scale may be inappropriate at this time, but experimentation with a diverse array of insect groups would probably provide valuable information.

The second impact of this study is on the development of potential management strategies for insecticide-resistant insect populations (organophosphateand carbamate-resistant western corn rootworms in this case). Results here show that rootworm populations with and without enhanced oxidative capabilities, ${ }^{8,10}$ and no apparent target site modification, ${ }^{6}$ are equally susceptible to fipronil. For this reason, fipronil may have the potential to be selectively toxic to some insect populations with highly active oxidative (cytochrome P450) xenobiotic-metabolizing systems. In addition to the development of an increased understanding of selective toxicity, further characterization of the oxidative enzymes involved could provide a means of identifying insect populations that could be effectively managed by a rotation-based resistance management strategy.

\section{ACKNOWLEDGEMENTS}

This work was supported in part by Rhone-Poulenc Ag Co (Research Triangle Park, NC, USA) and USDAARS specific cooperative agreement No. 58-5447-6116. Appreciation is extended to Dean Bushey and Jeff Holmsen (Rhone Poulenc) for correspondence and technical advice, to Jim Brown and Kanthriya Sukitjavanich (UNL) and Deb Hartman (USDA-ARS NGIRL) for beetle rearing and technical assistance. This is paper No. 12834 of the Journal Series of the University of Nebraska Agricultural Research Division, and Contribution No. 1044 of the Department of Entomology, University of Nebraska, Lincoln.

\section{REFERENCES}

1 Gant DB, Chalmers AE, Wolff MA, Hoffman HB and Bushey DF, Fipronil: action at the GABA receptor. Rev Toxicol 2:147156 (1998).

2 Valles SM, Koehler PG and Brenner RJ, Antagonism of fipronil toxicity by piperonyl butoxide and $S, S, S$-tributyl phosphorotrithioate in the German cockroach. F Econ Entomol 90:12541258 (1997).

3 Scott JG and Wen Z, Toxicity of fipronil to susceptible and resistant strains of German cockroaches and house flies. $\mathcal{F}$ Econ Entomol 90:1152-1156 (1997).

4 Cole LM, Nicholson RA and Casida JE, Action of phenylpyrazole insecticides at the GABA-gated chloride channel. Pestic Biochem Physiol 46:47-54 (1993).

5 Brookhart G and Bushey D, Tissue distribution and metabolism of fipronil administered orally to the southern armyworm. Proc 8th Internat Union Pure Appl Biochem -International Congress of Pesticide Chemistry, abstract No 189 (1995).

6 Scharf ME and Siegfried BD, Toxicity and neurophysiological effects of fipronil and fipronil-sulfone on the western corn rootworm. Arch Insect Biochem Physiol 40:150-156 (1999).

7 Meinke LJ, Siegfried BD, Wright RJ and Chandler LD, Adult susceptibility of Nebraska western corn rootworm populations to selected insecticides. F Econ Entomol 91:594-600 (1998).

8 Miota F, Scharf ME, Ono M, Marçon P, Meinke LJ, Wright RJ, Chandler LD and Siegfried BD, Mechanisms of methyl and ethyl parathion resistance in the western corn rootworm. Pestic Biochem Physiol 61:39-52 (1998).

9 Scharf ME, Meinke LJ, Siegfried BD, Wright RJ and Chandler LD, Carbaryl susceptibility, diagnostic concentration determination and synergism for US populations of western corn rootworm. J Econ Entomol 92:33-39 (1999).

10 Scharf ME, Meinke LJ, Wright RJ, Chandler LD and Siegfried BD, Metabolism of carbaryl by insecticide-resistant and susceptible western corn rootworm populations. Pestic Biochem Physiol 63:85-96 (1999).

11 Wright RJ, Scharf ME, Meinke LJ, Siegfried BD, Zhou X and Chandler LD, Larval susceptibility of an insecticide-resistant western corn rootworm population to soil insecticides: laboratory bioassays, assays of detoxification enzymes and field performance. F Econ Entomol 93:7-13 (2000).

12 Metcalf RL, Foreword, in Methods for the study of pest Diabrotica, ed by Krysan JL and Miller TA, Springer, New York. pp 7-15 (1986).

13 Jackson JJ, Rearing and handling of Diabrotica virgifera and Diabrotica undecimpunctata howardi, in Methods for the study of pest Diabrotica, ed by Krysan JL and Miller TA, Springer, New York, pp 25-47 (1986).

14 Robertson JL and Preisler HK, Pesticide Bioassays with Arthropods, CRC, Boca Raton (1992).

15 Lee SST and Scott JG, An improved method for preparation, stabilization and storage of house fly microsomes. $\mathcal{F}$ Econ Entomol 82:1559-1563 (1989).

16 Tang J, Siegfried BD and Hoagland KD, Glutathione- $S$ transferase and in vitro metabolism of atrazine in freshwater algae. Pestic Biochem Physiol 59:155-161 (1998).

17 Matsumura F, Toxicology of insecticides, Plenum, New York (1986).

$18 \mathrm{Yu}$ SJ, Insect glutathione-S-transferases. Zool Studies 35:9-19 (1996).

19 Bloomquist JR, Cyclodiene resistance at the insect GABA receptor/chloride channel complex confers broad cross-resistance to convulsants and experimental phenylpyrazole insecticides. Arch Insect Biochem Phys 26:69-79 (1994).

20 Bride JM, Cuany A, Amichot M, Brun A, Babault M, Le Mouel T, De Sousa G, Rahmani R and Berge JB, Cytochrome P450 field insecticide tolerance and development of laboratory resistance in grape vine populations of Drosophila melanogaster. f Econ Entomol 90:1514-1520 (1997). 